\title{
Gap difference in navigated TKA: a measure of the imbalanced flexion-extension gap
}

\author{
Zi-Yang Chia*, Hee-Nee Pang, Mann-Hong Tan, and Seng-Jin Yeo \\ Department of Orthopaedic Surgery, Singapore General Hospital, 20 College Road, Academia, Level 4, Singapore 169865, \\ Singapore
}

Received 14 December 2017, Accepted 27 February 2018, Published online 13 July 2018

\begin{abstract}
Introduction: The success of Total Knee Arthroplasty (TKA) hinges on balanced flexion-extension gaps. This paper aims to evaluate the correlation between imbalanced gaps and clinical outcomes, and hence help quantify the imbalanced gap in navigation-assisted total knee arthroplasty.

Methods: We studied 195 knees with an average follow-up of two years. Flexion-extension gaps were obtained from computer calculation upon cementation of implants in both flexion $\left(90^{\circ}\right)$ and extension. The gap difference (GD) was defined as the measured difference between the gaps in flexion and extension.

Results: At 2 years after surgery, the mean ROM in the balanced group, with GD less than or equal to $2 \mathrm{~mm}$, was $115.1^{\circ} \pm 16.6^{\circ}$ and the mean ROM in the imbalanced group was $116.7^{\circ} \pm 12.1^{\circ}$. This was not statistically significant with $p$-value 0.589 . Balanced flexion-extension gaps also did not show significant difference in terms of mechanical alignment, with $0.29 \pm 0.89$ in the balanced group at 2 years, and $0.65 \pm 1.51$ in the imbalanced group with $p$-value 0.123 . Balanced gaps however, were associated with improved outcomes in terms of physical functioning, bodily pain, social functioning, Oxford and Knee scores at 6 months and improved social functioning scores at 2 years.

Conclusions: Computer navigation is a useful tool for assessing the gap balance in TKA. Balanced flexionextension gaps, with gap differences of less than or equal to $2 \mathrm{~mm}$, is associated with improved clinical outcomes at 6 months.
\end{abstract}

Key words: Flexion extension gaps, Gap balancing, Navigated total knee arthroplasty, Computer assisted knee arthroplasty.

\section{Introduction}

Restoration of the mechanical axis and balanced flexion-extension gaps are factors for a successful total knee arthroplasty (TKA) [1,2]. Gap balancing influences the final knee kinematics [3] and incorrect soft tissue balancing can contribute to accelerated polyethylene wear [4]. Thus, balanced extension and flexion gaps are important [5]. Extension balance is affected by ligamental releases and flexion balance is affected by suitable collateral and posterior cruciate ligament (PCL) tension [6]. However, the optimal soft tissue balancing in conventional TKA is a perennial challenge as it is often an intuitive process [2], in particular the amount of PCL recession in cruciate-retaining (CR) TKA [7]. Computer navigation has been shown to be useful for correction of

\footnotetext{
*Corresponding author: chiaziyang@gmail.com
}

alignment [8] and more precise placement of implants in TKA [9]. It can also provide quantitative data to assess the flexion and extension gaps [10].

The current literature described the effects of nonrectangular gaps on clinical outcomes [11-15]. As yet, there are few reports on the effects of flexion-extension gap asymmetry on clinical outcomes. We hypothesized that asymmetry between flexion and extension gaps, adversely affects outcomes when it goes beyond a certain threshold. The aim of this study was to evaluate the correlation between flexion-extension gap asymmetry and clinical outcomes in computer assisted total knee arthroplasty.

\section{Materials and methods Study design}

Computer navigated TKA was performed on 195 consecutive patients (195 knees) in this prospective study after approval was sought for our study protocol from our 
hospital's ethics committee. The consent of all participating patients was obtained. The inclusion criterion was primary osteoarthritis of the knee. The exclusion criteria included patients with previous knee surgery, rheumatoid arthritis, infection and those who were unsuitable for unconstrained TKA. There were 155 females and forty males, with a mean age of 66.6 years (range, 50 to 90 years). The surgeries were done by the two senior surgeons (YSJ and TMH).

\section{Operative procedure}

Eighty three cruciate-retaining and 112 posterior stabilized (PS) TKAs were performed using metalbacked fixed-bearing tibial prostheses (PFC, Depuy Orthopaedic International, Leeds, UK). All patellae were resurfaced.

General or spinal anaesthesia was employed. 147 patients underwent spinal anaesthesia and 48 patients underwent general anaesthesia. Each surgery was done with the aid of a tourniquet after intravenous prophylactic antibiotic. The standard medial parapatellar approach was used with patellar eversion. All femurs were prepared after the tibiae, and the duration of the surgery was recorded at the end of the surgery.

The software used for the navigation assisted surgery was Ci Mi TKR Version 2.0 by BrainLab/ Depuy Orthopaedic Inc (Johnson and Johnson, Leeds, UK). Anatomical landmarks were registered with dual $3 \mathrm{~mm}$ unicortical pins inserted at a distance from the surgical approach, and a pointer with infrared reflectors. The tibial cut was performed first. This was followed by the femur cuts and ligament balancing. Soft tissue releases were done to produce a rectangular gap at 0 degrees extension and the space between the distal femur and proximal tibia was recorded. Subsequently, the knee was flexed to 90 degrees and the space between the posterior femoral condyles and proximal tibia stored. The use of navigation is beneficial as it helps to quantify the soft tissue tension in the gap balancing technique. The size and the position of the femoral component was adjusted on a virtual computer model to achieve equal extension and flexion gaps. Final flexion and extension gaps were then recorded after implantation of tibial and femoral components. The Gap Difference (GD) was determined by obtaining the difference between the flexion gap and the extension gap.

Our study demonstrated that increasing Gap Differences correlated with poor clinical outcomes. To find a specific Gap Difference threshold, the patients were divided into 2 groups based on varying Gap Differences. Sequential tests were then conducted with different GDs until the minimum value with statistical significance was obtained, which was found to be $2 \mathrm{~mm}$. Final flexionextension gap difference was thus defined as a difference in flexion and extension gaps of more than $2 \mathrm{~mm}$. Group A patients had Gap Differences of equal or less than $2 \mathrm{~mm}$, and Group B patients had Gap Differences of more than $2 \mathrm{~mm}$.
Each patient had graduated compression stockings and intermittent pneumatic calf pumps as prophylaxis against deep vein thrombosis. All patients had similar post operative analgesics regime and underwent the same rehabilitation protocol.

\section{Outcome measures}

The preoperative and outcome measures were evaluated by staff from our Orthopaedic Diagnostic Center at six months and two years postoperatively. The range of motion of each operated knee was assessed using a goniometer. The reading was repeated three times and the average measurement was used. Alignment was similarly measured in weightbearing at 6 months and 2 years during follow up.

The preoperative and postoperative functional status of the patients were evaluated using the Knee Society Clinical Rating Score [12], Oxford Knee Questionnaire [8] and SF-36 Health Survey.

\section{Statistical analysis}

Statistical analysis was performed with SPSS statistical software (version 17.0; SPSS, Chicago, Illinois). Univariate analysis was performed with Chisquare or the Fisher's exact test for comparison of proportions between two categorical data. The $t$-test was used to compare the parametric data between two independent samples. A $p$-value $<0.05$ was considered significant.

\section{Results}

The patients were divided into 2 groups, group A with Gap Differences less than or equal to $2 \mathrm{~mm}$, and Group B with Gap Differences more than $2 \mathrm{~mm}$. Group A had mean (SD) age of $66.1 \pm 8.0$ comprising 26 males and 98 females, whereas Group B had a mean (SD) age of $67.4 \pm 7.0$ years comprising 14 males and 57 females. There was no significant difference between the pre-operative alignment and the pre-operative ROM when comparing Group A to Group B. The length of stay, duration of surgery, proportion of CR vs PS knees also showed no significant difference between both groups.

\section{Intra-operative gap measurements}

Group A had a mean extension gap of $12.0 \mathrm{~mm} \pm 1.9$, and a mean flexion gap of $11.6 \mathrm{~mm} \pm 2.3$. Group B had a mean extension gap of $12.9 \mathrm{~mm} \pm 2.7$, and a mean flexion gap of $10.7 \mathrm{~mm} \pm 3.6$. The mean Gap Difference in Group A was $1.3 \pm 0.6$, and $3.8 \pm 1.5$ in Group B (Table 1).

\section{Range of motion}

In Group A, the ROM improved preoperatively from $112.3^{\circ} \pm 22.9^{\circ}$ to $115.1^{\circ} \pm 16.6^{\circ}$ at 2 years $(p=0.149)$. In Group B, the ROM improved preoperatively from $112.1^{\circ}$ $\pm 20.8^{\circ}$ to $116.7^{\circ} \pm 12.1^{\circ}$ at 2 years $(p=0.693)$. 
Table 1. Comparison of clinical measurements.

\begin{tabular}{llll}
\hline & $\begin{array}{l}\text { Group A } \\
\text { (GD less than or equal to 2 mm) }\end{array}$ & $\begin{array}{l}\text { Group B } \\
\text { (GD more than 2 mm) }\end{array}$ & $p$-value \\
\hline Range of motion (mean \pm stand. dev.) (degrees) & & $112.143 \pm 20.766$ & 0.962 \\
Preoperative & $112.3 \pm 22.865$ & $106.906 \pm 16.319$ & 0.232 \\
Postoperative at 6 months & $109.902 \pm 15.728$ & $116.7 \pm 12.107$ \\
Postoperative at 24 months & $115.061 \pm 16.577$ & & 0.589 \\
Mechanical axis (mean \pm stand. dev.) (degrees) & & $2.47 \pm 4.8$ & $0.55 \pm 1.511$ \\
Preoperative & $1.92 \pm 4.605$ & $0.65 \pm 1.511$ & 0.675 \\
Postoperative at 6 months & $0.45 \pm 1.535$ & 0.123 \\
Postoperative at 24 months & $0.29 \pm 0.89$ & & 0.431 \\
\hline
\end{tabular}

\section{Alignment}

The alignment in Group A improved from preoperative coronal plane alignment of $1.92^{\circ} \pm 4.605^{\circ}$, to $0.29^{\circ} \pm 0.9^{\circ}$ at 2 years $(p=0.00)$. The alignment in Group $\mathrm{B}$ improved from pre-operative coronal plane alignment of $2.5^{\circ} \pm 4.8^{\circ}$, to $0.7^{\circ} \pm 1.5^{\circ}$ at 2 years $(p=0.007)$.

\section{Knee society scores and oxford knee scores (Table 2)}

Group A patients showed improved outcomes in clinical scores, such as the Knee Society Score and Oxford Knee Score (OKS), at 6 months with significance. However, the outcomes for both groups were comparative with no significance at 2 years. At 6 months post-operation, the proportion of patients who had excellent results in the Knee Score (score $\geq 80$ ) in Group A was $79.6 \%$, as compared to $64.0 \%$ in Group B $(p=0.032)$. In terms of Function Scores, Group A had $42.2 \%$ with excellent results, while Group B had $33.3 \%(p=0.27)$. The proportion of patients who had excellent results in OKS (score < 24) in Group A was 91.4\%, as compared to $74.2 \%$ in Group B $(p=0.004)$. At 2 years post-operation, the proportion of patients who had excellent results in the Knee Score (score $\geq 80$ ) in Group A was $86.6 \%$, as compared to $87.5 \%$ in Group B $(p=0.570)$. In terms of Function Score, Group A had $50 \%$ of patients with excellent scores, and Group B had 40\% ( $p=0.210)$ The proportion of patients who had excellent results in OKS (score <24) in Group A was $91.2 \%$, as compared to $85.0 \%$ in Group B $(p=0.248)$.

\section{Complications}

One patient (1.4\%) in each group had superficial infection which responded to IV antibiotics, one patient in group B had distal DVT. There no revisions performed during the two year follow up.

\section{Discussion}

Balanced flexion-extension gaps are essential for good outcomes in TKA. However it is still an intuitive process, based on subjective feeling. The use of computed navigation has improved gap balancing [16], mechanical alignment [17] and implant positioning. This paper aims to correlate gap difference with clinical outcomes, and to quantify the imbalanced flexion extension gap.

Imbalanced flexion-extension gaps results in decreased postoperative range-of-motion, as well as poorer functional scores and increased rates of implant failures [18-21]. A study performed by Hiroshi et al. [11] over 4 years reported positive correlation between ROM and gap difference. By affecting the final knee kinematics, imbalanced gaps lead to suboptimal soft tissue balance, and therefore accelerated polyethylene wear, as well as increasing likelihood of flexion deformity $>4^{\circ}[22]$. In the event of a tight flexion gap, measures can be taken intraoperatively to balance the gap. The posterior slope of the tibia can be increased up to 7 degrees if flexion gap tightness is felt to be secondary to tightness of both collateral ligaments and the posterior cruciate ligament [6]. The posterior cruciate ligament can be released when it is determined to be excessively tight while the collateral ligaments is deemed balanced. In addition, one can consider femoral recession and conversion from CR to PS TKA [23].

Other studies have different means of gap measurement, using spacers and lamina spreaders under specific joint distraction forces $[24,25]$. In this study, although gaps were measured and balanced after bone morphing, final gaps as analysed here were only recorded after implantation. This was done without the use of lamina spreaders. Hence, this data is limited to correlating postimplantation gaps with clinical outcomes. It should be noted that this post-implantation gap is affected by other factors such as implant size and placement, hence it is only a surrogate marker of soft tissue balance. This study can be improved by measuring pre-implantation gaps under specific distraction forces, the results of which will have greater clinical utility in correcting imbalances before final implantation. In addition, if post-implantation gaps can be shown to have good correlation with pre-implantation gaps, then the results of this study can likewise have improved clinical significance.

We find navigation beneficial as it allows us to create rectangular gaps, minimizing medial-lateral asymmetry [16]. It also helps to balance the flexion and extension gap, and to quantify the tight flexion gap after implantation. 
Table 2. Comparison of clinical data.

\begin{tabular}{|c|c|c|c|}
\hline & $\begin{array}{l}\text { Group A (GD less than } \\
\text { or equal to } 2 \mathrm{~mm} \text { ) }\end{array}$ & Group B (GD more than $2 \mathrm{~mm}$ ) & $p$-value \\
\hline \multicolumn{4}{|l|}{ Knee score (mean \pm stand. dev.) } \\
\hline Preoperative & $39.187 \pm 21.041$ & $38.681 \pm 17.548$ & 0.859 \\
\hline Postoperative at 6 months & $83.876 \pm 9.695$ & $77.644 \pm 16.758$ & 0.010 \\
\hline Postoperative at 24 months & $87.026 \pm 10.690$ & $83.741 \pm 15.909$ & 0.161 \\
\hline \multicolumn{4}{|l|}{ Function Score (mean \pm stand. dev.) } \\
\hline Preoperative & $56.138 \pm 17.436$ & $54.058 \pm 20.62$ & 0.459 \\
\hline Postoperative at 6 months & $70 \pm 15.628$ & $65.167 \pm 19.614$ & 0.084 \\
\hline Postoperative at 24 months & $74.740 \pm 19.295$ & $67.870 \pm 21.070$ & 0.056 \\
\hline \multicolumn{4}{|c|}{ Oxford Knee Score (mean \pm stand. dev.) } \\
\hline Preoperative & $33.943 \pm 8.202$ & $35.275 \pm 8.881$ & 0.296 \\
\hline Postoperative at 6 months & $18.933 \pm 4.74$ & $22.783 \pm 8.853$ & 0.003 \\
\hline Postoperative at 24 months & $18.376 \pm 4.721$ & $20.0926 \pm 6.983$ & 0.120 \\
\hline \multicolumn{4}{|l|}{ SF-36 Score (mean \pm stand. dev.) } \\
\hline \multicolumn{4}{|l|}{ Physical Functioning (PF) } \\
\hline Preoperative & $41.179 \pm 21.596$ & $22.826 \pm 36.314$ & 0.644 \\
\hline Postoperative at 6 months & $65.809 \pm 19.723$ & $57.666 \pm 22.819$ & 0.017 \\
\hline Postoperative at 24 months & $69.350 \pm 18.413$ & $62.314 \pm 23.963$ & 0.073 \\
\hline \multicolumn{4}{|l|}{ Role-Physical (RP) } \\
\hline Preoperative & $28.252 \pm 39.717$ & $35.159 \pm 18.356$ & 0.350 \\
\hline Postoperative at 6 months & $69.762 \pm 40.975$ & $55.833 \pm 45.185$ & 0.045 \\
\hline Postoperative at 24 months & $70.779 \pm 38.984$ & $62.037 \pm 42.819$ & 0.227 \\
\hline \multicolumn{4}{|l|}{ Bodily Pain (BP) } \\
\hline Preoperative & $36.26 \pm 18.995$ & $35.159 \pm 18.356$ & 0.697 \\
\hline Postoperative at 6 months & $66.209 \pm 26.394$ & $55.05 \pm 24.823$ & 0.008 \\
\hline Postoperative at 24 months & $66.012 \pm 23.771$ & $61.092 \pm 25.817$ & 0.263 \\
\hline \multicolumn{4}{|l|}{ General Health (GH) } \\
\hline Preoperative & $71.2114 \pm 17.928$ & $64.405 \pm 19.755$ & 0.016 \\
\hline Postoperative at 6 months & $73.2 \pm 18.104$ & $68.4 \pm 21.607$ & 0.129 \\
\hline Postoperative at 24 months & $71.883 \pm 20.778$ & $68.018 \pm 22.389$ & 0.312 \\
\hline \multicolumn{4}{|l|}{ Vitality } \\
\hline Preoperative & $68.821 \pm 20.725$ & $67.826 \pm 19.336$ & 0.744 \\
\hline Postoperative at 6 months & $75.857 \pm 18.507$ & $70.083 \pm 20.284$ & 0.650 \\
\hline Postoperative at 24 months & $74.350 \pm 17.646$ & $70.370 \pm 17.720$ & 0.207 \\
\hline \multicolumn{4}{|l|}{ Social functioning (SF) } \\
\hline Preoperative & $61.991 \pm 37.752$ & $55.435 \pm 36.03$ & 0.242 \\
\hline Postoperative at 6 months & $88.214 \pm 25.229$ & $69.583 \pm 36.921$ & 0.000 \\
\hline Postoperative at 24 months & $94.318 \pm 18.864$ & $82.870 \pm 31.407$ & 0.019 \\
\hline \multicolumn{4}{|l|}{ Role Emotional (RE) } \\
\hline Preoperative & $85.095 \pm 33.93$ & $78.261 \pm 39.534$ & 0.209 \\
\hline Postoperative at 6 months & $94.92 \pm 19.492$ & $87.778 \pm 31.87$ & 0.120 \\
\hline Postoperative at 24 months & $96.536 \pm 17.592$ & $96.296 \pm 19.062$ & 0.941 \\
\hline \multicolumn{4}{|l|}{ Mental health } \\
\hline Preoperative & $79.317 \pm 17.388$ & $77.449 \pm 17.136$ & 0.474 \\
\hline Postoperative at 6 months & $84.266 \pm 13.024$ & $78.8 \pm 16.798$ & 0.320 \\
\hline Postoperative at 24 months & $84.051 \pm 12.740$ & $83.037 \pm 14.452$ & 0.672 \\
\hline
\end{tabular}


No studies have provided readily quantifiable values for the definition of an imbalanced flexion-extension gap. In our study, patients with imbalanced gaps of more than $2 \mathrm{~mm}$ difference have poorer clinical outcomes at 6 months. This is useful for intra-operative gap balancing to improve clinical outcomes.

The patients in Group A had superior Knee Scores at 6 months, which is the objective component of the Knee Society Score. This difference could be influenced by the improved ROM seen in Group A at 6 months. However, at 2 years, this difference in ROM is equalized, which could help explain the similar Knee scores at 2 years for both groups.

Some of the improvement in objective outcomes translated into improved clinical scores at 6 months, as evidenced by the superior Oxford Knee Scores in Group A. However, the differences in the OKS did not show up in the SF-36 scores. This is possibly because the OKS is kneespecific, as opposed to the SF-36 which is a marker for general health, hence differences seen in the OKS were not significant enough to show up on the SF-36 scores.

We acknowledge that given the number of patients in Group B, it may be perceived that a substantial proportion of knees are not adequately balanced. However, the $2 \mathrm{~mm}$ benchmark is an arbitrary threshold, and there is currently a lack of a widely-accepted definition of a balanced knee. Nonetheless, this illustrates that even with computer navigation, to produce balanced flexion and extension gaps, one has to achieve appropriate soft tissue balancing, bone cuts, and implant choice.

The effects of imbalanced gaps could be further studied by focusing on the sub-group of patients with gap differences of more than $3 \mathrm{~mm}$. At the same time however, the senior authors acknowledge that the gap differences revealed by the computer navigation may not accurately reflect the intra-operative gap difference.

By incorporating the use of navigation-assisted surgery, this paper aims to quantify the imbalanced flexion-extension gap by studying 2 year outcomes. Long term studies could however be done on the effects of gap difference, and how this correlates to the difference (if any) in outcomes between navigation-assisted surgery and conventional TKRs.

Limitations. Given the relative short timeline, we were not able to gather data to demonstrate improved outcomes in the long term. Long term results will be useful to study the effects on imbalanced gaps on outcomes such as polyethylene wear.

Our study has incorporated both CR and PS type TKAs done by both surgeons alike. The controversy over the superiority of either types of TKA continues as both show no significant difference in outcomes.

We acknowledge that the gap difference measured after bone cuts, with a tensiometer, is a better indicator of soft tissue balance. This will better guide the extent of soft tissue releases required to achieve balanced gaps, hence improved clinical outcomes.

In conclusion, computer navigation is a useful tool for providing quantitative data in correlating balanced gaps with clinical outcomes. This study also demonstrated that patients with balanced flexion-extension gaps, with gap differences of less than or equal to $2 \mathrm{~mm}$, show improved clinical outcomes at 6 months.

\section{Conflict of interest}

The authors declare that they have no conflicts of interest in relation to this article.

\section{References}

1. Freeman MA, Todd RC, Bamert P, et al. (1978) ICLH Arthroplasty of the knee: 1968-1977. J bone Jt Surg Br 60-B(3), 339-344.

2. Insall JN, Binazzi R, Soudry M, et al. (1985) Total knee arthroplasty. Clin Orthop 192, 13-22.

3. Insall JN, Easley ME (2001) Surgical techniques and instrumentation in total knee arthroplasty. In: Surgery of the Knee, 3rd ed. Insall JN (ed). Churchill Livingston, Philadelphia, pp. 1553-1557.

4. Crottet D, Kowal J, Sarfert SA, Maeder T, Bleuler H, Nolte LP, Durselen L (2007) Ligament balancing in TKA: evaluation of a force-sensing device and the influence of patellar eversion and ligament release. J Biomech 40(8), 1709-1715.

5. Insall JN (1988) Presidential address to The Knee Society. Choices and compromises in total knee arthroplasty. Clin Orthop 226, 43-48.

6. Lombardi AV Jr, Berend KR, Aziz-Jacobo J, Davis MB. (2008) Balancing the flexion gap: relationship between tibial slope and posterior cruciate ligament release and correlation with range of motion. J Bone Joint Surg Am 90(Suppl 4), 121-132.

7. Straw R, Kulkarni S, Attfield S, Wilton TJ (2003) Posterior cruciate ligament at total knee replacement. Essential, beneficial or a hindrance? J Bone Jt Surg Br 85(5), 671-674.

8. Bauwens K, Matthes G, Wich M, Gebhard F, Hanson B, Ekkernkamp A, Stengel D (2007) Navigated total knee replacement. A meta-analysis. J Bone Joint Surg Am 89(2), 261-269.

9. Chin PL, Yang KY, Yeo SJ, Lo NN (2005) Randomized control trial comparing radiographic total knee arthroplasty implant placement using computer navigation versus conventional technique. J Arthroplasty 20(5), 618-626.

10. Matsumoto T, Muratsu H, Tsumura N, et al. (2009) Soft tissue balance measurement in posterior-stabilized total knee arthroplasty with a navigation system. J Arthroplasty 24(3), 358-364.

11. Higuchi H, Hatayama K, Shimizu M, et al. (2009) Relationship between joint gap difference and range of motion in total knee arthroplasty: a prospective randomized study between different platforms. Int Orthop 33, 997.

12. Romero J, Stahelin T, Binkert C, et al. (2007) The clinical consequences of flexion gap asymmetry in total knee arthroplasty. J Arthroplasty 22, 235.

13. Unitt L, Sambatakakis A, Johnstone D, et al. (2008) Shortterm outcome in total knee replacement after soft-tissue release and balancing. J Bone Jt Surg Br 90-B, 159.

14. Lee DS, Song EK, Seon JK, Park SJ (2010) Effect of Balanced Gap Total Knee Arthroplasty on Intraoperative Laxities and Femoral Component Rotation. J Arthroplasty 19. [Epub ahead of print]. 
15. Seon JK, Song EK, Park SJ, Lee DS (2010) The Use of Navigation to Obtain Rectangular Flexion and Extension Gaps During Primary Total Knee Arthroplasty and Midterm Clinical Results. J Arthroplasty 24. [Epub ahead of print].

16. Pang HN, Yeo SJ, Chong HC, et al. (2011) Computerassisted Gap Balancing Technique Improves Outcome in Total Knee Arthroplasty, Compared With Conventional Measured Resection Technique. Knee Surg Sports Traumatol Arthrosc 30. [Epub ahead of print].

17. Chin PL, Yang KY, Yeo SJ, Lo NN (2005) Randomized control trial comparing radiographic total knee arthroplasty implant placement using computer navigation versus conventional technique. J Arthroplast 20, 618-626.

18. Takahashi T, Wada Y, Yamamoto H (1997) Soft-tissue balancing with pressure distribution during total knee arthroplasty. J Bone Joint Surg 79, 235.

19. Bottros J, Gad B, Krebs V, Barsoum WK (2006) Gap balancing in total knee arthroplasty. J Arthroplasty 21(4) Suppl 1, 11-15.
20. Fehring TK, Odum S, Griffin WL, Mason JB, Nadaud M (2001) Early failures in total knee arthroplasty. Clin Orthop Relat Res 392, 315-318.

21. Sharkey PF, Hozack WJ, Rothman RH, Shastri S, Jacoby SM (2002) Why are total knee arthroplasties failing today? Clin Orthop Relat Res 404, 7-13.

22. Mullaji A, Sharma A, Marawar S, et al. (2009) Quantification of Effect of Sequential Posteromedial Release on Flexion and Extension Gaps. J Arthroplasty 24, 795.

23. In Y, Kim JM, Woo YK, et al. (2009) Factors Affecting Flexion Gap Tightness in Cruciate-Retaining Total Knee Arthroplasty. J Arthroplasty 24, 317.

24. Ranawat AS, Ranawat CS, Elkus M, Rasquinha VJ, et al. (2005) Total Knee Arthroplasty for Severe Valgus deformity. J Bone Joint Surg Am 87, 271-284.

25. Lee DH, Park JH, Song DI, et al. (2010) Accuracy of soft tissue balancing in TKA: comparison between navigationassisted gap balancing and conventional measured resection. Knee Surg Sports Traumatol Arthrosc 18, 381-387.

Cite this article as: Chia ZY, Pang HN, Tan MH, Yeo SJ (2018) Gap difference in navigated TKA: a measure of the imbalanced

flexion-extension gap. SICOT-J, 4, 30. 